physiological index of myocardial reserve and thus at inefficient ratios, may predispose to reduced exercise capacity.

Methods Using RV conductance catheterisation and contemporaneous incremental cardiopulmonary exercise testing, we evaluated Ees/Ea against peak $\mathrm{VO}_{2}$ in twenty patients with pulmonary vascular disease. Ees/Ea was compared with haemodynamic predictors of exercise capacity obtained from standard right heart catheterisation.

Results Resting Ees/Ea, absolute peak $\mathrm{VO}_{2}$ and predicted peak $\mathrm{VO}_{2}$ were $0.86 \pm 0.40,19.6 \pm 6.7 \mathrm{ml} / \mathrm{Kg} / \mathrm{min}$ and $88 \pm 23 \%$ respectively. Univariable predictors of absolute peak $\mathrm{VO}_{2}$ were patient gender, NYHA class, mean right atrial pressure, mean pulmonary artery pressure, cardiac index, conductance RV stroke volume and Ees/Ea (all $\mathrm{p}<0.10$ ). On bivariate analysis, the predictive value of Ees/Ea improved following adjustment for RV stroke volume $(\mathrm{p}=0.03)$ but not for mean RA pressure $(\mathrm{p}=0.21)$. Only Ees/Ea related linearly to percent predicted $\mathrm{VO}_{2}\left(\mathrm{R}^{2}=0.32, \mathrm{p}=0.01\right) . \mathrm{RV}$ diastolic decay $\left(-\mathrm{dP} / \mathrm{dt}_{\min }\right)$ showed good correlation with $\mathrm{O}_{2}$ pulse evolution $(\mathrm{r}=0.62, \mathrm{p}$ $<0.01$ ) although no single haemodynamic parameter differentiated absolute peak $\mathrm{VO}_{2}$ above and below its median value.

Discussion VA coupling is a marker of RV energetic efficiency and adds to the debate on the multifactorial determinants of exercise capacity in $\mathrm{PH}$. Ees/Ea was comparable to other predictive haemodynamic parameters of exercise capacity and may represent the 'recruitable' myocardial reserve, important for maintaining cardiac output at increased metabolic demand. Ees/Ea may be a potential therapeutic target given the unclear relationship between pulmonary haemodynamics and patient symptoms.

\begin{tabular}{|c|c|c|c|c|}
\hline & \multicolumn{2}{|c|}{ Univariable analysis } & \multicolumn{2}{|c|}{ Univariable analysis } \\
\hline & \multicolumn{2}{|c|}{ Peak $\mathrm{VO}_{2} \mathrm{ml} / \mathrm{Kg} / \mathrm{min}$} & \multicolumn{2}{|c|}{ Peak $\mathrm{VO}_{2} \%$ predicted } \\
\hline & $\beta$ & P Value & $\beta$ & P Value \\
\hline \multicolumn{5}{|l|}{ Clinical } \\
\hline Age & -0.16 & 0.50 & 0.22 & 0.34 \\
\hline Gender & 0.53 & 0.02 & -0.25 & 0.29 \\
\hline BSA & -0.33 & 0.16 & -0.25 & 0.30 \\
\hline NYHA Class & -0.62 & $<0.01$ & -0.18 & 0.44 \\
\hline \multicolumn{5}{|l|}{ Swan Ganz } \\
\hline Mean RAP $(\mathrm{mmHg})$ & -0.42 & 0.06 & -0.30 & 0.21 \\
\hline mPAP $(\mathrm{mmHg})$ & -0.56 & 0.01 & -0.38 & 0.10 \\
\hline Cardiac Index (L/min/m2) & 0.60 & $<0.01$ & 0.21 & 0.38 \\
\hline \multicolumn{5}{|l|}{ Conductance } \\
\hline RVSW & -0.12 & 0.61 & -0.37 & 0.11 \\
\hline sv & 0.39 & 0.09 & -0.08 & 0.74 \\
\hline Ees $(\mathrm{mmHg} / \mathrm{ml})$ & 0.06 & 0.79 & -0.18 & 0.45 \\
\hline Ea $(\mathrm{mmHg} / \mathrm{ml})$ & -0.29 & 0.22 & -0.34 & 0.14 \\
\hline $\mathrm{Ca}(\mathrm{ml} / \mathrm{mmHg})$ & 0.33 & 0.16 & 0.14 & 0.54 \\
\hline Ees/Ea & 0.45 & 0.04 & 0.56 & 0.01 \\
\hline
\end{tabular}

\section{S49 THE DIAGNOSTIC VALUE OF MEASURING AAG DURING EXERCISE IN PATIENTS WITH PULMONARY HYPERTENSION}

B Mukherjee, E Chan, K Murphy, H Tighe, R Davies, S Gibbs, L Howard; Hammersmith Hospital, Imperial College, London, UK

10.1136/thoraxjnl-2013-204457.56
The exercise response in pulmonary hypertension $(\mathrm{PH})$ has characteristic features, including decreased peak oxygen consumption (VO2-peak), increased ventilatory inefficiency (VE/ $\mathrm{VCO} 2$ slope) and widened alveolar-arterial oxygen-gradient (AaG). We wished to evaluate if the AaG at peak exercise predicted those patients likely to have $\mathrm{PH}$ who would subsequently require catheter studies.

Methods We performed a retrospective analysis of patients referred to Hammersmith Hospital between Feb 2008 and Feb 2012 for investigation of Pulmonary Hypertension $(\mathrm{PH})$ who underwent cardiopulmonary exercise testing (CPX) with testing of AaG using arterial blood gas analysis at peak exercise. Patients found to have alternative cardiac or respiratory diagnoses were excluded. Patients given diagnoses of Pulmonary Arterial Hypertension or Pulmonary Hypertension due to Left Heart Disease and with temporally coincident data from CPX and RHC (within 3 months) were included. Patients without cardiorespiratory diagnoses were healthy controls. The VE/VCO2 slope and AaG were compared to the diagnosis of $\mathrm{PH}$ and the trans-pulmonary pressure gradient (TPG), (the difference between mean pulmonary artery pressure (mPAP) and pulmonary capillary wedge pressure (PCWP) or left ventricular end diastolic pressure (LVEDP) where available).

Results Using logistic regression to predict a diagnosis of $\mathrm{PH}$, AaG had an odds ratios of 2.98 ( $\mathrm{p}<0.01)$ and receiver operating characteristic curve for sensitivity and specificity had area under the curve (ROC-AUC) of 0.92. An AaG cut-off of $2.5 \mathrm{kPA}$ had $90 \%$ sensitivity and $80 \%$ specificity. Similarly, VE/VCO2 had an odds ratio of $1.21(\mathrm{p}<0.01)$ and ROC-AUC 0.85 for predicting $\mathrm{PH}$. Combining AaG and VE/VCO2 had ROC-AUC of 0.94 for diagnosing $\mathrm{PH}$ without significant interaction between $\mathrm{AaG}$ and VE/VCO2. For predicting a TPG $>12 \mathrm{mmHg}$, $\mathrm{AaG}$ had an odds ratios of $4.54(\mathrm{p}<0.01)$ and ROC-AUC of 0.95 . VE/VCO2 had an odds ratio of $1.10(\mathrm{p}<0.01)$ and ROCAUC 0.74 for predicting TPG $>12 \mathrm{mmHg}$.

Conclusion CPX has become part of the diagnostic workup of patients with $\mathrm{PH}$. AaG measured at peak exercise has a high sensitivity and specificity in predicting patients with $\mathrm{PH}$, which may help determining which patients will require invasive catheter studies. The AaG provides independent information than VE/VCO2 alone in predicting $\mathrm{PH}$ and may be useful in the investigation of $\mathrm{PH}$.

\section{S50 HYPERSENSITIVITY PNEUMONITIS COMPLICATED BY PULMONARY HYPERTENSION; PATIENT CHARACTERISTICS AND RESPONSE TO TARGETED THERAPY}

BE Garfield, GJ Keir, LC Price, AU Wells, E Renzoni, TM Maher, P Marino, K Dimopoulos, SJ Wort; Royal Brompton and Harefield NHS Foundation Trust, London, UK;

\subsection{6/thoraxjnl-2013-204457.57}

Background Hypersensitivity pneumonitis (HP) results from repeated exposure to a sensitizing antigen, normally an organic particle. It can be acute, sub-acute or chronic (1). There is very little literature describing the association of pulmonary hypertension $(\mathrm{PH})$ with HP (2). We aimed to summarize the clinical characteristics and outcomes including responses to targeted therapy in patients with $\mathrm{HP}$ and $\mathrm{PH}$ in a tertiary referral centre.

Methods Cases diagnosed between 1992 and 2008 were identified through a central database. $\mathrm{PH}$ was defined as mean pulmonary artery pressure $\geq 25 \mathrm{mmHg}$ on right heart catheter or right ventricular systolic pressure of $\geq 50 \mathrm{mmHg}$ on echocardiogram. Data was collected through case note and electronic record review. Analysis was performed using Graphpad prism. 